\title{
Factor structure of the Dispositional Hope Scale amongst South Africans: An exploratory structural equation modelling study
}

Authors:
Itumeleng P. Khumalo ${ }^{1}$
Tharina Guse
Affiliations:
'Department of Psychology,
Faculty of Humanities,
University of the Free State,
Bloemfontein, South Africa
2Department of Psychology,
Faculty of Humanities,
University of Pretoria,
Pretoria, South Africa
Research Project Registration:
Project Number: OPT-2014-
012
code with your
Corresponding author:
Itumeleng Khumalo,
khumaloip@ufs.ac.za
to read online.
Dates:
Read online:
Received: 05 July 2021
Accepted: 30 Sept. 2021
Published: 31 Jan. 2022
How to cite this article:
Khumalo, I.P., \& Guse, T.
(2022). Factor structure of the
Dispositional Hope Scale
amongst South Africans: An
exploratory structural equation
modelling study. African
Journal of Psychological
Assessment, 4(0), a66. https://
doi.org/10.4102/ajopa.v4i0.66
Copyright:
C 2022. The Authors.
Licensee: AOSIS. This work
is licensed under the
Creative Commons
Attribution License.

Snyder's model of hope conceptualises and operationalises hope as a cognitive, trait-like bi-dimensional future-oriented construct consisting of pathways thinking and agency thinking for goal achievement. The present study implemented exploratory structural equation modelling (ESEM) and confirmatory factor analysis (CFA) on the Dispositional Hope Scale, using data from two South African student samples ( $n=383,48 \%$ female, 21.70 years average age and $n=251,68 \%$ female, 20.55 years average age), with the aim to examine its factor structure in an African context. The results showed that a six item unidimensional solution of hope fit the data best. This model characterises hope as the ability to make plans, informed by past experiences and to spontaneously manoeuvre around obstacles as any situation may call for it. This finding has implications for the measurement of hope and development of emic operational models in an African context.

Keywords: hope; Dispositional Hope Scale; measurement; structural equation modelling; factor analysis.

\section{Introduction}

The study of hope, as a goal-directed and future-oriented concept, features prominently as a focus of scientific inquiry in positive psychology (Seligman \& Csikszentmihalyi, 2000; Snyder, 2004). Although it shares conceptual similarity with a number of other future-oriented constructs (Krafft, Martin-Krumm, \& Fenouillet, 2017), hope is defined as a cognitive and dispositional process that involves agency and pathways for reaching one's goals (Snyder, 1995, 2002, 2004; Snyder, Cheavens, \& Sympson, 1997; Snyder et al., 1991). Other goal-directed constructs include optimism (Alarcon, Bowling, \& Khazon, 2013; Scheier \& Carver, 1985), self-efficacy (Bandura, 1977, 1997), meaning in life (Schnell, 2009; Steger, 2012), curiosity (Kashdan et al., 2009) and motivation (ed. Ryan, 2012). Hope differs from these concepts because it foregrounds all the three goal-pursuit elements, namely agency, pathways and goals, equally (Marques, Lopez, Rose, \& Robinson, 2014). Whilst pathways thinking refers to the perceived ability to generate routes that lead to the desired goals, agentic thinking represents the cognitive willpower or energy, which propels people to move towards their goals (Snyder, 1995). Thus, high hope 'reflects an elevated sense of mental energy and pathways for goals' (Snyder, 1995, p. 355).

Initially thought to be too vague to study and measure (see Snyder, 1995), hope in addition to Snyder's model (Snyder, 1995, 2002; Snyder et al., 1991), is now conceptualised and operationalised through a plethora of approaches (e.g. Bernardo, 2010; Krafft et al., 2017; Maree \& Maree, 2005; Maree, Maree, \& Collins, 2008; Scioli, Ricci, Nyugen, \& Scioli, 2011). Perceived hope refers to the conception of hope as perceived and experienced by ordinary people and encompassing spiritual, religious and altruistic dimensions (Krafft et al., 2017). Locus of hope is described as 'whether the components of trait hope involve internal or external agents and internally or externally generated pathways' (Bernardo, 2010, p. 945). Conceptualising hope expressed as an emotion, Scioli et al. (2011) proposed integrated hope as a future-directed, four-channel emotion network made up of mastery, attachment, survival and spiritual systems. Maree (Maree \& Maree, 2005; Maree et al., 2008) measured hope as a multidimensional construct comprising goal achievement resources, ineffectuality, future vision, despondency and agency, which subsequently enables perseverance, anchoring and direction. Even before the cognitivemotivational model of Snyder, two older models attempting to explain hope, with their own variations, were developed by Stotland (1969) and Averil, Catlin and Chon (1990). Nevertheless, there is consensus across all of these models that hope represents a positive expectation towards future outcomes (Krafft et al., 2017). 
Hope is important because people are intrinsically goal oriented and tend to think about their future (Emmons, 2003; ed. Ryan, 2012; Snyder, 1995). Higher levels of hope are positively associated with life satisfaction (O'Sullivan, 2011), positive affect and positive and rational problem solving styles (Chang \& Banks, 2007). Previous studies amongst university students found that high hope was associated with health benefits, such as diet regulation and exercise (Berg, Ritschel, Swan, An, \& Ahluwalia, 2011), academic success (Snyder et al., 2002), adjustment to university (Liu, Kia-Keating, \& Modir, 2017) and well-being (Demerli, Türkmen, \& Arik, 2015; Guse \& Shaw, 2018). Conversely, hope was negatively associated with anxiety and depression (Arnau, Rosen, Finch, Rhudy, \& Fortunato, 2007; Snyder et al., 1991), negative affect, negative problem orientation and an impulsive problem solving style (Chang \& Banks, 2007). Hope may serve as a protective factor in the mental health outcomes of youth (Griggs, 2017) and can have therapeutic value as it may enhance well-being and preserve health (Krafft et al., 2017). Having hope also makes young people more likely to invest in their future, for example, through attaining education and avoiding risky health behaviours that may be detrimental to their future (Graham \& Pozuelo, 2018). In counselling psychology settings (Snyder, 1995) and cross culturally (Chang \& Banks, 2007), the measurement of targeted outcome variables such as hope is crucial for accurate diagnostic information. The present study is specifically concerned with how hope is measured using the Dispositional Hope Scale (DHS) (Snyder et al., 1991) in a group of students in South Africa.

Recognising that confirmatory factor analysis (CFA) has generally been used to examine the construct validity of multi-item instruments comprising hypothesised factors (Pretorius, 2021), our study extends this work by applying exploratory structural equation modelling (ESEM) to the DHS in South Africa. The importance of knowing and working with the confidence that a measuring instrument has good psychometric properties in the specifically applied context cannot be overstated (Pretorius, 2021).

A number of international studies have investigated and reported a variety of findings on the measurement quality and dimensionality of the DHS (e.g. Abdel-Khalek \& Snyder, 2007; Demirli, Türkmen, \& Arik, 2015; Gana, Daigre, \& Ledrich, 2013; Kemer \& Atik, 2012; Roesch \& Vaughn, 2006; Sun, Ng, \& Wang, 2012; Venning, Eliott, Kettler, \& Wilson, 2009). Most have relied on multivariate analysis and/or CFA. However, the limitations of CFA are increasingly demonstrated in empirical studies (Perry, Nicholls, Clough, \& Crust, 2015). Using a large multi-ethnic sample in the United States of America (US), Roesch and Vaughn (2006) found support for the two-factor sample of the DHS. Sun et al. (2012) similarly found a two-factor model amongst three Chinese samples. The two-factor structure was confirmed in several other studies implemented amongst French (Gana et al., 2013), Australian (Venning et al., 2009) and Arabic-speaking (Abdel-Khalek \& Snyder, 2007) samples.
However, a few other studies did not find the theoretically intended two-factor structure. Arnau et al. (2007) arrived at a view that agency and pathways components did not make unique contributions to the construct of hope. Following bifactor analysis, Brouwer et al., (2008) recommended that the DHS should be implemented as a unidimensional scale, as the items measure the same construct, with very little unique variance being explained by two separate dimensions. Similarly, using CFA, Espinoza et al. (2017) reported that a unidimensional model best fit the data when examining hope in general and clinical populations. Choi, Lee and Lee (2008) reported a unidimensional structure amongst Korean undergraduate students, whilst Park and Kim (2017) found support for the two-factor structure amongst Korean stroke survivors. Similar studies in (South) Africa include those of Guse, De Bruin and Kok (2016) and Savahl, Casas and Adams (2016) who reported the psychometric properties of the Children's Hope Scale (Snyder et al., 1997b) and Nel and Boshoff (2014) who reported the psychometric properties of the Adult State Hope Scale (Snyder et al., 1996).

Confirmatory factor analysis has been extensively used to investigate the factor structure of many measuring instruments in psychology and related fields (BenitezBorrego, Guardia-Olmos, \& Urzua-Morales, 2014). The limitations of CFA include its restrictive tendency of requiring zero cross-loadings and overestimating interfactor correlations (Perry et al., 2015). According to Asparouhov and Muthen (2009), exploratory factor analysis (EFA) would be an alternative solution when the overly restrictive CFA does not fit the data well. Exploratory structural equation modelling (Asparouhov \& Muthen, 2009), conducted in Mplus, was our preferred approach for adequately and comprehensively exploring the factor structure of the DHS amongst South African students. The advantages of ESEM, over CFA, are that it allows for the modelling of (theoretically plausible) cross-loadings, and it has less reliance on model modification indexes. In this way, it provides greater modelling flexibility in being a less restrictive way of estimating measurement models, thus allowing for broader and richer a priori model alternatives (Asparouhov \& Muthen, 2009). The ESEM has been helpful in clarifying factor structure of (psychological) well-being measures in parts of the world such as Iran (e.g. Joshanloo, 2016a, 2016b). At the time of conducting this study, we were not aware of studies using ESEM to explore the factor structure of Snyder's conceptual model of hope. Given the contradictory results concerning the factor structure of the DHS, the absence of evidence for the applicability of the DHS in the African context and the limitations of CFA, we further investigated its factor structure using ESEM.

The value of this exercise is underscored by cross-cultural transportation and adaptation of measuring instruments (Chen, 2008; Joshanloo, 2016a; Wissing et al., 2010). Although hope may be considered a globally recognised concept (Snyder, 2004; Sun et al., 2012), cross-cultural transportation and adaptation of measurement cannot ignore group 
differences in personhood and ways of being. Whilst some studies have supported the assumption of universality (e.g. Roesch \& Vaugn, 2006), others have not (e.g. Brouwer et al., 2008; Choi et al., 2008; Galiana, Oliver, Sancho, \& Tomás, 2015). To date, evidence of the applicability of the two-factor model of hope and its context informed nature is lacking in African samples. This is notwithstanding the observation by Krafft et al. (2017, p. 3) that the 'central questions in the design of hope studies have been the dimensionality and complexity (unidimensional or multidimensional) of the concept'.

Given the possible differences in socio-cultural characteristics of (South) Africans such as time perspective, uncertainty avoidance, individualism-collectivism and cultural tightnesslooseness (Khumalo, Wilson, \& Brouwers, 2020), the implementation of ESEM could yield a unique/emic dimensional solution of hope. No studies applying ESEM Asparouhov \& Muthen, 2009) could be located. The present study is therefore concerned with investigating the factor structure of hope, as measured by the DHS, a widely used measure of hope in positive psychology (Ackerman, Warren, \& Donaldson, 2018). It is in this context that the exploration of the factor structure of the DHS using a more flexible statistical analysis approach was necessary.

\section{Method}

\section{Participants and setting}

Data were collected from two samples of students from two different institutions of higher learning situated in the most urbanised province of South Africa. The first sample comprised 383 students ( $48 \%$ female, 21.70 average of age [SD $=2.36]$ ) from a University of Technology and the second sample of 251 students (68\% female, 20.55 average of age [SD = 1.95]) from a comprehensive university.

\section{Measuring instrument Dispositional Hope Scale}

The DHS (Snyder et al., 1991) is designed as a two-factor solution measure, consisting of 12 items meant to provide scores on agency-thinking (4 items) and pathways-thinking (4 items), and a combined summative score of hope. The four additional items are distractor items. It uses an 8-point Likert-type scale ranging from 1 (definitely false) to 8 (definitely true). The agency-thinking item content is exemplified by 'I energetically pursue my goals', and pathways-thinking by 'There are lots of ways around any problem'. The DHS has been found to be reliable, with Snyder et al. (1991) reporting Cronbach's alpha coefficients of between 0.74 and 0.84 amongst students, as well as outpatients and inpatients in psychological treatment. In the same study, the agency subscale attained a Cronbach's alpha coefficient ranging between 0.71 and 0.76 and the pathways subscale between 0.63 and 0.80 . Later studies reported similar reliability coefficients (e.g. Galiana et al., 2015; Roesch \& Vaughn, 2006). Research examining the DHS in different cultural contexts further supported its validity (e.g. Demirli et al., 2015; Galiana et al., 2015; Kemer \& Atik, 2012; Roesch \& Vaughn, 2006; Sun et al., 2012). In the present study, based on the intended factor structure, the pathways subscale obtained an omega reliability index of 0.725 for sample 1 and 0.810 for sample 2, whilst the agency subscale scored 0.644 for sample 1 and 0.823 for sample 2. The reliability for the total scale as a unidimensional measure was 0.810 for sample 1 and 0.881 for sample 2 .

\section{Data analysis}

The present study investigated the model fit of the DHS measurement models in two independent samples using CFA and ESEM in Mplus (Muthén \& Muthén, 1998-2017). Before commencing with factor analytic investigation, we computed the item-level descriptive statistics of the hope scale. As recommended by Marsh, Morin, Parker and Kaur (2014), we used maximum likelihood estimation, with oblique geomin rotation. The following measurement models were fitted and evaluated for fit in both samples separately: one-factor solution, two-factor CFA solution and two-factor ESEM solution. The following model fit indices and criteria were used to judge the adequacy of the models: chi-square $\left(\chi^{2}\right)$, root mean square error of approximation (RMSEA), standardised root mean square residual (SRMR); comparative fit index (CFI), Tucker-Lewis index (TLI); Akaike Information Criterion (AIC) and Bayesian Information Criterion (BIC) (Geiser, 2013). For good fit, the following criteria were used: smaller and insignificant $\chi^{2}$, RMSEA and SRMR of less than 0.06; CFI of more than 0.95; TLI of more than 0.95; smaller AIC and smaller BIC (Byrne, 2012; Geiser, 2013; Hu \& Bentler, 1999; Wang \& Wang, 2012).

\section{Ethical considerations}

All participants were informed volunteers, recruited via their lecturers by research assistants who were postgraduate students. The participants from the Vaal University of Technology completed the battery of questionnaires after signing an informed consent letter and returned the completed questionnaires after a week. At the University of Johannesburg (the comprehensive university), the students completed the questionnaire online after providing informed consent. Participants did not receive incentives. Ethical clearance was obtained from North-West University (reference number: NWU-00138-14-A8), Vaal University of Technology (reference number: 20140425-1ms) and the University of Johannesburg (reference number: REC $01-009-2015)$.

\section{Results}

\section{Sample 1}

Model fit indices are reported in Table 1. The two CFA models of the DHS had good but not excellent fit. The unidimensional model $\left(\chi^{2}[20]=84.68, p<0.000\right.$, CFI $=0.917)$ was relatively comparable with the theoretically intended bidimensional one $\left(\chi^{2}[19]=84.129\right.$, 
TABLE 1: Fit indices for unidimensional, CFA bidimensional, and ESEM bidimensioanl models for sample 1 and sample 2.

\begin{tabular}{|c|c|c|c|c|c|c|c|c|c|c|c|c|}
\hline Variable & $X^{2}$ & Df & $p$ & AIC & BIC & CFI & TLI & RMSEA & LL & UL & $p$ & SRMR \\
\hline \multicolumn{13}{|c|}{ Sample $1(n=383)$} \\
\hline 1 Factor & 84.680 & 20 & $<0.0000$ & 10603 & 10697 & 0.917 & 0.884 & 0.092 & 0.072 & 0.0113 & $<0.000$ & 0.052 \\
\hline 2 Factors CFA & 84.129 & 19 & $<0.0000$ & 10604 & 10703 & 0.916 & 0.877 & 0.095 & 0.075 & 0.1160 & $<0.000$ & 0.052 \\
\hline 2 Factors ESEM & 25.417 & 13 & 0.0203 & 10557 & 10680 & 0.984 & 0.966 & 0.050 & 0.019 & 0.0790 & 0.461 & 0.026 \\
\hline \multicolumn{13}{|c|}{ Sample $2(n=251)$} \\
\hline 1 Factor & 97.555 & 20 & $<0.0000$ & 6890 & 6975 & 0.912 & 0.877 & 0.124 & 0.100 & 0.1490 & $<0.000$ & 0.050 \\
\hline 2 Factors CFA & 65.526 & 19 & $<0.0000$ & 6860 & 6949 & 0.947 & 0.922 & 0.099 & 0.073 & 0.1250 & 0.001 & 0.125 \\
\hline 2 Factors ESEM & 28.060 & 13 & 0.0089 & 6835 & 6944 & 0.983 & 0.963 & 0.068 & 0.033 & 0.1030 & 0.176 & 0.024 \\
\hline
\end{tabular}

CFA, confirmatory factor analysis; ESEM, exploratory structural equation modelling; Df, degrees of freedom; AIC, Akaike Information Criterion; BIC, Bayesian Information Criterion; CFI, comparative fit index; TLI, Tucker-Lewis index; RMSEA, root mean square error of approximation; LL, lower limit; UL, upper limit; SRMR, standardised root mean square residual.

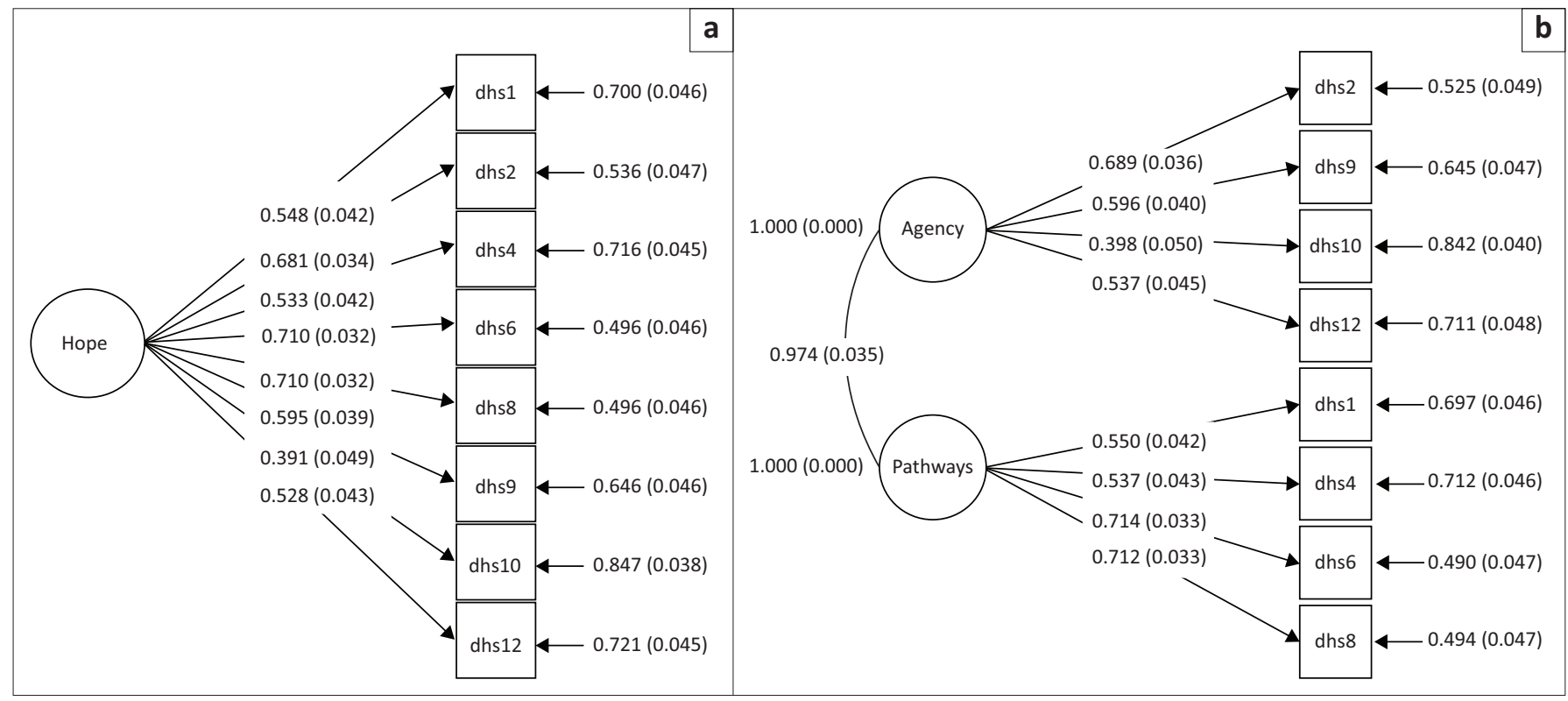

FIGURE 1: The confirmatory factor analysis (CFA) models for sample $1(n=383)$. (a) The unidimensional solution, and, (b) the two-factor solution.

TABLE 2: Descriptive statistics: Sample $1(n=383)$, based on confirmatory factor analysis two-factor model.

\begin{tabular}{lcccccc}
\hline Variable & Mean & Variance & Minimum & Maximum & Skewness & Kurtosis \\
\hline Agency & & & & & & \\
Item 2 & 6.574 & 1.868 & 1 & 8 & -1.012 & 1.022 \\
Item 9 & 6.822 & 2.318 & 1 & 8 & -1.345 & 1.269 \\
Item 10 & 5.679 & 2.547 & 1 & 8 & -0.631 & 0.423 \\
Item 12 & 5.922 & 2.312 & 1 & 8 & -0.678 & 0.301 \\
Pathways & & & & & & \\
Item 1 & 6.141 & 2.805 & 1 & 8 & -0.927 & 0.499 \\
Item 4 & 6.326 & 2.575 & 1 & 8 & -0.968 & 0.631 \\
Item 6 & 6.561 & 1.969 & 1 & 8 & -0.840 & 0.249 \\
Item 8 & 6.363 & 2.325 & 1 & 8 & -0.877 & 0.398 \\
\hline
\end{tabular}

$p<0.000$, CFI $=0.916)$. Reliability indices and the itemlevel descriptive statistics, as seen in Table 2, for the agency and pathways subscales were computed based on the two-factor model. Mean scores ranged between 5.68 and 6.82 and all the skewness and kurtosis values attested to normal distribution of data. The unidimensional and bidimensional CFA models for sample 1 are displayed in Figure 1.

The ESEM model demonstrated a significant improvement $\left(\chi^{2}[13]=25.417, p=0.0203, \mathrm{CFI}=0.984\right)$. The latent variables, agency and pathways had a high correlation of 0.974 in the CFA bidimensional model. As seen in Figure 2,

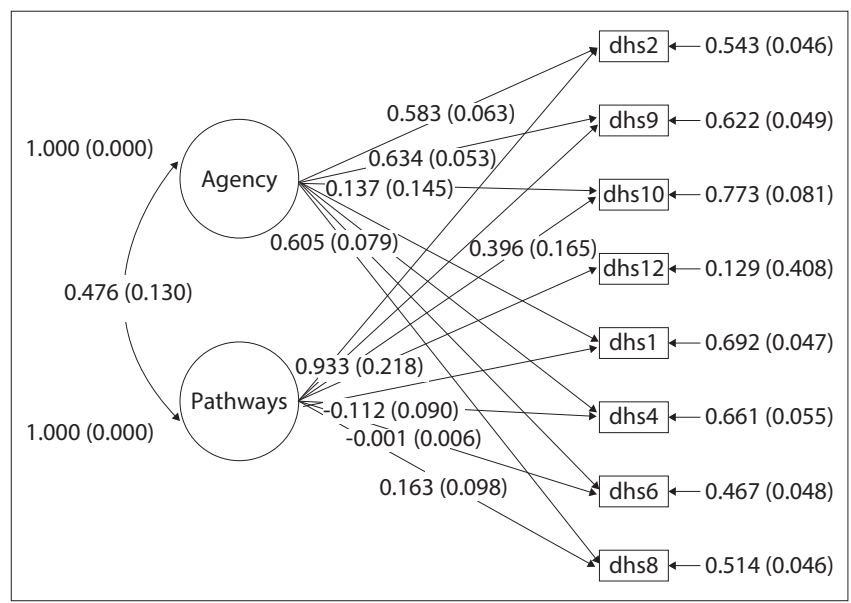

FIGURE 2: The exploratory structural equation modelling two-factor solution for sample $1(n=383)$.

the resultant two factors in the ESEM model had a moderate correlation of 0.476 .

As seen in Table 3, all the items obtained significant factor loadings on the latent variables in both the CFA and ESEM models. The ESEM produced a two dimensional solution with agency consisting of six items and pathways having two items. All the theoretically intended pathways items load significantly on the agency factor. This left two agency items 
TABLE 3: Standardised factor loadings of the two-factor models. Subscales and item content

\begin{tabular}{|c|c|c|c|c|c|}
\hline \multicolumn{3}{|c|}{ Sample 1} & \multicolumn{3}{|c|}{ Sample 2} \\
\hline \multicolumn{2}{|c|}{ ESEM } & \multirow[t]{2}{*}{ CFA } & \multicolumn{2}{|c|}{ ESEM } & \multirow[t]{2}{*}{ CFA } \\
\hline Agency & Pathways & & Agency & Pathways & \\
\hline 0.583 & 0.164 & 0.689 & 0.409 & 0.392 & 0.744 \\
\hline 0.634 & -0.044 & 0.596 & 0.489 & 0.261 & 0.697 \\
\hline 0.137 & 0.396 & 0.398 & 0.041 & 0.717 & 0.714 \\
\hline 0.000 & 0.933 & 0.537 & -0.006 & 0.876 & 0.775 \\
\hline 0.536 & 0.037 & 0.550 & 0.490 & 0.066 & 0.544 \\
\hline 0.627 & -0.112 & 0.537 & 0.765 & -0.081 & 0.695 \\
\hline 0.730 & -0.001 & 0.714 & 0.695 & 0.130 & 0.807 \\
\hline 0.605 & 0.163 & 0.712 & 0.833 & -0.003 & 0.809 \\
\hline
\end{tabular}

\section{Agency}

Item 2: I energetically pursue my goals

Item 9: My past experiences have prepared me well for my future

Item 10: I have been pretty successful in life

Item 12: I meet the goals that I set for myself

Pathways

Item 1: I can think of many ways of getting out of a jam

Item 4: There are lots of ways around any problem

Item 6: I can think of many ways to get the things in life that are important to me

0.712

Note: Factor loadings in bold are significant on the basis of being higher than 0.35 . There is no additional coefficient or statistic to accompany it.

CFA, confirmatory factor analysis; ESEM, exploratory structural equation modelling.

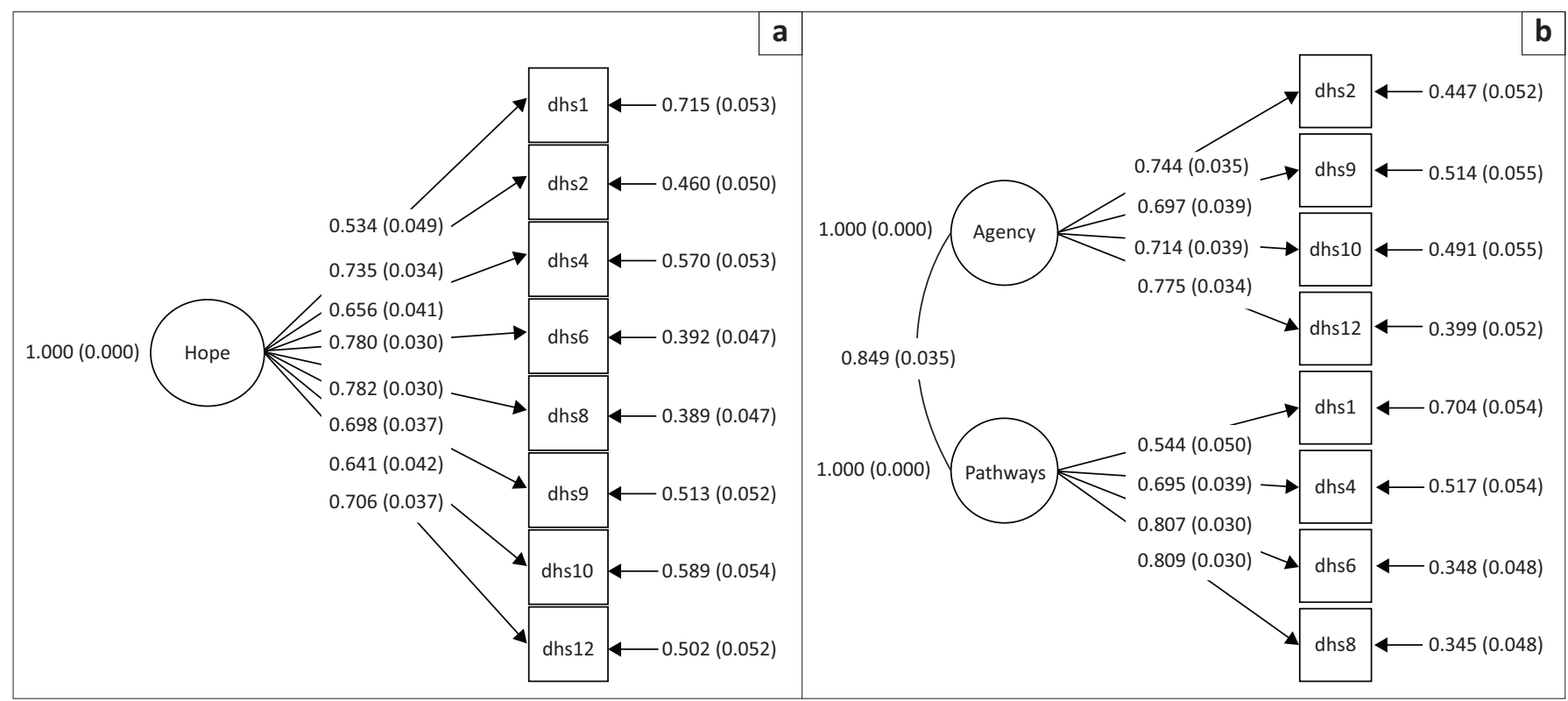

FIGURE 3: The confirmatory factor analysis (CFA) models for sample $2(n=251)$. (a) The unidimensional solution, and, (b) the two-factor solution.

TABLE 4: Descriptive statistics: Sample $2(n=251)$, based on confirmatory factor analysis two-factor model.

\begin{tabular}{lcccccc}
\hline Variable & Mean & Variance & Minimum & Maximum & Skewness & Kurtosis \\
\hline Agency & & & & & & \\
Item 2 & 6.064 & 2.402 & 1 & 8 & -0.851 & 0.247 \\
Item 9 & 6.689 & 2.382 & 1 & 8 & -1.332 & 1.530 \\
Item 10 & 5.614 & 3.535 & 1 & 8 & -0.725 & -0.103 \\
Item 12 & 5.582 & 2.865 & 1 & 8 & -0.932 & 0.756 \\
Pathways & & & & & & \\
Item 1 & 5.928 & 2.425 & 1 & 8 & -0.843 & 0.627 \\
Item 4 & 6.347 & 2.585 & 1 & 8 & -0.959 & 0.447 \\
Item 6 & 6.084 & 2.523 & 1 & 8 & -0.728 & 0.080 \\
Item 8 & 6.279 & 2.791 & 1 & 8 & -1.184 & 1.060 \\
\hline
\end{tabular}

to make up the pathways subscale. No cross loading items were observed.

\section{Sample 2}

Similarly, in sample 2, the ESEM model proved to be superior (see Table 1). The CFA models from sample 2 are displayed in Figure 3. Both of them had acceptable, but not excellent model fit (Hu \& Benlter, 1999), with the unidimensional one characterised by $\chi^{2}(20)=97.555, p<0.000, \mathrm{CFI}=0.912$ and the bidimensional one by $\chi^{2}(19)=65.526, p<0.000, \mathrm{CFI}=0.947$. Reliability indices and the item-level descriptive statistics, as seen in Table 4, for the agency and pathways yielded mean scores ranging between 5.61 and 6.69 and the skewness and kurtosis values showed a normal distribution. Notably, the ESEM model demonstrated a significant improvement $\chi^{2}(13)=28.060, p=0.0089, \mathrm{CFI}=0.983$. The correlation coefficient between agency and pathways was 0.849 in the CFA bidimensional model and 0.671 in the ESEM bidimensional model.

All the items obtained significant factor loadings on the latent variables in both the CFA and ESEM models, as also found in sample 1 (see Table 3). Except for one important difference between sample 1 and sample 2, in this sample, ESEM produced a two dimensional solution, with agency consisting of six items, and pathways having two items. All the theoretically intended pathways items load significantly on the agency factor and two agency items made up the pathways subscale. Of notable interest was that item 2 cross loaded (see Figure 4). 


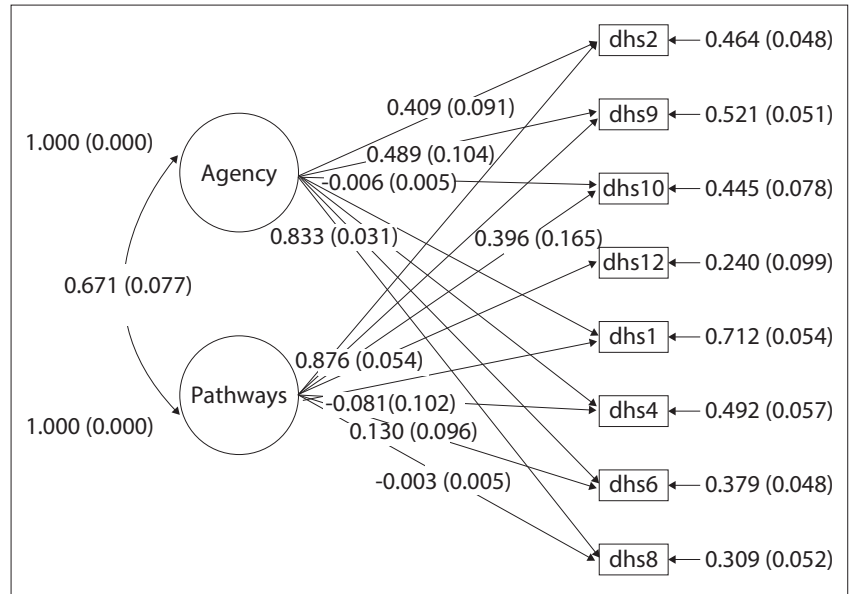

FIGURE 4: The exploratory structural equation modelling two-factor solution for sample $2(n=251)$.

\section{Discussion}

This study sought to provide further evidence of the dimensionality of hope, as operationalised through the DHS of Snyder et al. (1991), using a more flexible factor analysis approach, ESEM (Asparouhov \& Muthen, 2009), amongst a South African sample. Not only was the necessity for this study driven by the statistical analytical approach and the African socio-cultural context, but we wanted to contribute to the current body of knowledge where there seems to be a lack of consensus about the measurement of hope. The importance of measurement in a context such as South Africa is also underscored by the legal and ethical obligation for culturally appropriate and psychometrically sound measures (Adams, Van de Vijver, \& De Bruin, 2012). We found that a six item unidimensional solution of hope was best fitting. This was in contrast to the one-factor and the theoretically intended twofactor CFA models, which did not have excellent fit in our data.

Our data did not support a unidimensional solution consisting of eight items, as this factor structure yielded sub-adequate model fit indices in both samples. This finding contradicts previous research, which suggested that the eight items of the DHS explained hope as one factor. In one such study, Brouwer et al. (2008) found that the two separate dimensions explained very little unique variance. In other studies, the unidimensional solution was used from the onset. Examples include Guse and Vermaak (2011) who used the total score for the Children's Hope Scale in South Africa, and Hirschi (2014) who used the DHS total score with student and working adult samples in Germany. Although the two-factor CFA model seemed promising in the present data, it was marginally inadequate in both samples. As expected, these theoretically intended CFA models showed very high inter latent variable correlations of 0.974 (sample 1) and 0.849 (sample 2). At face value, this result may suggest that hope may possibly be better operationalised as a unidimensional solution. It is also known that the overestimation of inter-factor correlation is a result of the over restrictive CFA, which constrains items to load only on the one intended factor (Marsh, Liem, Martin, Morin, \& Nagengast, 2011; Perry et al., 2015).
As a result of the inherent flexibility of ESEM (Joshanloo 2016a; Marsh et al., 2011), we expected that the two factor ESEM model would demonstrate superior fit and moderate inter-factor correlations. Indeed, the application of ESEM yielded a more nuanced and possibly emic distribution of the DHS items. The use of ESEM resulted in a model with one major factor consisting of six items and one minor factor consisting of two items. In both samples, lower interfactor correlations were observed, with 0.476 for sample 1 , and 0.671 for sample 2, thus demonstrating inter-factor independence. As seen in Table 4, all four items theoretically intended to indicate pathways thinking (e.g. 'There are lots of ways around a problem') loaded on the agency factor together with two agentic thinking items, namely 'I energetically pursue my goals', and 'My past experiences have prepared me well for my future'. The two agentic thinking items that loaded on the separate minor factor were 'I have been pretty successful in life', and 'I meet the goals that I set for myself'. A closer look at the item content of these two separately loading items tells us of the participants' non-endorsement of the assumption of past success and meeting self-determined goals.

The ESEM factorial solution may be best interpreted as indicating an emic six item unidimensional measure of hope characterised as the ability to make plans, informed by past experiences and to spontaneously manoeuvre around obstacles as any situation may call for it. We therefore see an intertwined hybrid of practical wisdom and the will to achieve success. Practical wisdom is broadly described by Furey (2017) as the use of subjective and contextual resources in response to real life situations and not relying only on contemplative knowledge. This disposition, also known as phronesis, equips a person with an ability to view situations from multiple perspectives and to 'navigate a variety of contextually complex situations' (Furey, 2017, p. 473). Ryff and Singer (1998, p. 6) have thought of practical wisdom, which they described as 'excellence of thought that guides good action' as a moral virtue in an African sociocultural context.

The assumption of past success and the expectation of meeting self-set goals do not form part of this picture. It is not uncommon that when one's past is uncertain, it cannot be used as a source of hope for the future (see Bryant \& Elland, 2015). As observed by Cherrington (2018), hope is not only drawn from personal narratives of individualised success but is contextually nurtured in a collective sphere. Instead, the foregrounded characteristic of this dimension is confidence in practical problem solving informed by past experiences and executed with vitality. This dimension is reminiscent of the factor labelled by Maree et al. (2008) as agency. In the development and validation of their multidimensional hope measure, Maree et al. (2008) conceived of this factor as the 'ability to focus and act' (p. 172), belief that goals can be achieved by doing something and representing situational ability to energise 
oneself. The finding not only holds implications for how dispositional hope becomes measurable but also how it is conceptualised in this context.

In a region of the world characterised by uncertainty, where there is also a cultural orientation of being comfortable with unstructured situations, having tolerance for ambiguity (i.e. low uncertainty avoidance; Allik \& McCrae, 2004; Hofstede, 2011) and being present and past time-oriented (Mbiti, 1990, 1991), more collectivistic (Wissing \& Temane, 2008) and culturally tight (Khumalo et al., 2020), it may not be the individual but the greater social ecology, which sets the demarcations of the goaloriented journey to be embarked on. According to Bishop and Willis (2014, p. 782) 'hopeful thinking is necessary for the construction of a positive self-identity and positive sense of self-worth', but what if it only serves as a pragmatic mechanism towards everyday goals. In their study amongst marginalised youth in Australia, Bryant and Elland (2015) found that many participants could not articulate a future beyond their present circumstances and concluded that their uncertainties shaped their future thinking. These findings underscore the importance of context in measuring and understanding hope.

\section{Limitations}

The findings of this study are to be interpreted in the context of its limitations. Notwithstanding the strength of utilising two independent datasets, data were still obtained from university students through convenience sampling. Future studies should consider more systematic and inclusive forms of sampling applied to larger, diverse and more representative population samples. There is also a need for bottom-up informed conceptual and operational models of hope in an African context (e.g. Bishop \& Willis, 2014; Cherrington, 2018). In addition to ESEM, as we did, quantitative data on hope, need to be subjected to more sophisticated statistical analysis approaches such as Rasch analysis/item response theory, multi-dimensional scaling, bifactor analysis and latent class analysis. Through such approaches in different and representative samples, a better understanding of item functioning and dimensionality of hope scales in an African context can be gained.

\section{Conclusion and recommendations}

Hope is a psychological strength that holds relevance for a number of life domains and intervention avenues. It is a determinant for students' success (Feldman, Davidson, \& Margalit, 2014), as much as it is relevant for health psychology (Snyder, 1995) and for counselling psychology setting (Cheavens, Feldman, Woodward, \& Snyder, 2006). As hope is malleable (Weis \& Speridakos, 2011) and associated with several positive mental health outcomes for students (Berg et al., 2011; Griggs, 2017), the DHS could be used in evaluating the effect of interventions to enhance hope amongst South African students. The fact that our ESEM results did not support the previous theoretically and empirically supported Snyder's model of hope is a possible illustration of either measurement instability (as seen in Khumalo, Ejoke, Asante, \& Rugira, 2021) and or poor contextually embedded support (perhaps based on cultural interpretation) of a cross culturally transported theoretical construct (see Cherrington, 2018).

Recommendations for further research include further investigation of the psychometric properties of the DHS by examining measurement invariance across gender and ethnicity, which may play a role in participants' responses to some of the items. Further studies could implement the DHS to investigate the dynamics of hope and well-being amongst South African university students. This is particularly important given the current context of higher education in South Africa, as access to university remains limited to a small percentage of school leavers, many of whom do not complete their studies (Habib, 2016). There also is a need to evaluate interventions to enhance hope amongst African samples and youth in particular. In conclusion, our study extended research on hope theory by providing support for psychometric properties of the DHS in an African student sample. It paves the way for further research on hope and well-being in the African context, thereby expanding knowledge of human flourishing beyond existing Western understanding.

\section{Acknowledgements Competing interests}

The authors have declared that no competing interest exists.

\section{Authors' contributions}

I.P.K. and T.G. both contributed equally to the realisation of the article. This contribution includes conceptualisation, contribution of data, methodology and data analysis and writing.

\section{Funding information}

This research received no specific grant from any funding agency in the public, commercial or not-for-profit sectors.

\section{Data availability}

The authors confirm that the data supporting the findings of this study are available within the article. Raw data that support the findings of this study are available from the corresponding author I.P.K., upon reasonable request.

\section{Disclaimer}

The views and opinions expressed in this article are those of the authors and do not necessarily reflect the official policy or position of any affiliated agency of the authors, and the publisher. 


\section{References}

Abdel-Khalek, A., \& Snyder, C.R. (2007). Correlates and predictors of an Arabic translation of the Snyder Hope Scale. Journal of Positive Psychology, 2(4), 228-235. https://doi.org/10.1080/17439760701552337

Ackerman, C.E., Warren, M.A., \& Donaldson, S.I. (2018). Scaling the heights of positive psychology : A systematic review of measurement scales. International Journal of Wellbeing, 8(2), 1-21. https://doi.org/10.5502/ijw.v8i2.734

Adams, B.G., Van de Vijver, F.J.R., \& De Bruin, G.P. (2012). Identity in South Africa: Examining self-descriptions across ethnic groups. International Journal of Intercultural Relations, 36(3), 377-388. https://doi.org/10.1016/j.ijintrel.2011. 11.008

Alarcon, G.M., Bowling, N.A., \& Khazon, S. (2013). Great expectations: A meta-analytic examination of optimism and hope. Personality and Individual Differences, 54(7) 821-827. https://doi.org/10.1016/j.paid.2012.12.004

Allik, J., \& McCrae, R.R. (2004). Towards a geography of personality traits: Patterns of profiles across 36 cultures. Journal of Cross-Cultural Psychology, 35(1), 13-27. profiles across 36 cultures. Journal of Cross-Cultur
https://doi.org/10.1177\%2F0022022103260382

Arnau, R.C., Rosen, D.H., Finch, J.F., Rhudy, J.L., \& Fortunato, V.J. (2007). Longitudinal effects of hope on depression and anxiety: A latent variable analysis. Journal of Personality, 75(1), 43-64. https://doi.org/10.1111/j.1467-6494.2006.00432.x

Asparouhov, T., \& Muthen, B. (2009). Exploratory structural equation modelling. Structural Equation Modelling: A Multidisciplinary Journal, 16(3), 397-438. https://doi.org/10.1080/10705510903008204

Averil, J.R., Catlin, G., \& Chon, K.K. (1990). Rules of hope. New York, NY: Springer.

Bandura, A. (1977). Self-efficacy: Toward a unifying theory of behavior change. Psychological Review, 84(2), 191-215. https://doi.org/10.1037/0033 295X.84.2.191

Bandura, A. (1997). Self-efficacy: The exercise of control. New York, NY: Freeman.

Benitez-Borrego, S., Guardia-Olmos, J., \& Urzua-Morales, A. (2014). Factorial structural analysis of the Spanish version of WHOQOL-BREF: An exploratory
structural equation model study. Quality of Life Research, 23, 2205-2212. https:// doi.org/10.1007/s11136-014-0663-2

Berg, C.J., Ritschel, L.A., Swan, D.W., An, L.C., \& Ahluwalia, J.S. (2011). The role of hope in engaging in healthy behaviours among college students. American Journal of Health Behaviour, 35(4), 402-415. https://doi.org/10.5993/AJHB.35.4.3

Bernardo, A.B. (2010). Extending hope theory: Internal and external locus of trait hope. Personality and Individual Differences, 49(8), 944-949. https://doi. org/10.1016/j.paid.2010.07.036

Bishop, E.C., \& Willis, K. (2014). 'Without hope everything would be doom and gloom': Young people talk about the importance of hope in their lives. Journal of Youth Young people talk about the importance of hope in their lives. Journal of
Studies, 17(6), 778-793. https://doi.org/10.1080/13676261.2013.878788

Brouwer, D., Meijer, R.R., Weekers, A.M., \& Baneke, J.J. (2008). On the dimensionality of the Dispositional Hope Scale. Psychological Assessment, 20(3), 310. https://doi. org/10.1037/1040-3590.20.3.310

Bryant, J., \& Elland, J. (2015). Hope as a form of agency in the future thinking of disenfranchised young people. Journal of Youth Studies, 18(4), 485-499. https:// doi.org/10.1080/13676261.2014.992310

Byrne, B.M. (2012). Structural equation modeling with mplus: Basic concepts, applications, and programming. New York, NY: Routledge.

Chang, E.D., \& Banks, K.H. (2007). The color and texture of hope: Some preliminary finding and implications for hope theory and counselling among diverse racial/
ethnic groups. Cultural Diversity and Ethnic Minority Psychology, 13(2), 94-103. ethnic groups. Cultural Diversity and Ethnic
https://doi.org/10.1037/1099-9809.13.2.94

Cheavens, J.S., Feldman, D.B., Woodward, J.T., \& Snyder, C.R. (2006). Hope in cognitive psychotherapies: On working with client strengths. Journal of Cognitive psychotherapies: On work
Psychotherapy, 20(2), 135.

Chen, F.F. (2008). What happens if we compare chopsticks with forks? The impact of making inappropriate comparisons in cross-cultural research. Journal of Personality and Social Psychology, 95(5), 1005-1018. https://doi.org/10.1037/a0013193

Cherrington, A.M. (2018). A framework of Afrocentric hope: Rural South African children's conceptualizations of hope. Journal of Community Psychology, 46(4), 1-13. https://doi.org/10.1002/jcop.21956

Choi, Y.H., Lee, H.K., \& Lee, D. (2008). Validation of the Korean version of Snyder's Dispositional Hope Scale. Korean Journal of Social per Psychology, 22(2), 1-16.

Demirli, A., Türkmen, M., \& Arik, R.S. (2015). Investigation of dispositional and state hope levels' relations with student subjective well-being. Social Indicators Research, 120, 601-613.

Emmons, R.A. (2003). The psychology of ultimate concerns: Motivation and spirituality in personality. New York, NY: The Guilford Press.

Espinoza, M., Molinari, G., Etchemendy, E., Herrero, R., Botella, C., \& Rivera, R.M.B. (2017). Understanding dispositional hope in general and clinical populations. Applied Research in Quality of Life, 12(2), 439-450. https://doi.org/10.1007/ s11482-016-9469-4

Feldman, D.B., Davidson, O.B., \& Margalit, M. (2014). Personal resources, hope, and achievement among college students: The conservation of resources perspective. Journal of Happiness Studies, 16, 543-560. https://doi.org/10.1007/s10902-014-9508-5

Furey, H. (2017). Aristotle and autism: Reconsidering a radical shift to virtue ethics in engineering. Science and Engineering Ethics, 23, 469-488. https://doi-org.ufs. idm.oclc.org/10.1007/s11948-016-9787-9

Galiana, L., Oliver, A., Sancho, P., \& Tomás, J.M. (2015). Dimensionality and validation of the Dispositional Hope Scale in a Spanish sample. Social Indicators Research, $120(1), 297-308$. https://doi.org/10.1007/s11205-014-0582-1
Gana, K., Daigre, S., \& Ledrich, J. (2013). Psychometric properties of the French version of the adult Dispositional Hope Scale. Assessment, 20(1), 114-118. https://doi.org/10.1177\%2F1073191112468315

Geiser, C. (2013). Data analysis with Mplus. New York, NY: Guilford Press.

Graham, C., \& Ruiz Pozuelo, J. (2018). Does hope lead to better futures? Evidence from a survey of the life choices of young adults in Peru. Global Economy and Development. Working Papers 2018-038. Human Capital and Economic Opportunity Working Group. Retrieved from http://dx.doi.org/10.13140/ RG.2.2.12816.71686

Griggs, S. (2017). Hope and mental health in young adult college students: An integrative review. Journal of Psychosocial Nursing and Mental Health Services, 55(2), 28-35. https://doi.org/10.3928/02793695-20170210-04

Guse, T., De Bruin, G.P., \& Kok, M. (2016). Validation of the children's hope scale in a sample of South African adolescents. Child Indicators Research, 9(3), 757-770. https://doi.org/10.1007/s12187-015-9345-z

Guse, T., \& Shaw, M. (2018). Hope, meaning in life and well-being among a group of young adults. In A. Krafft, P. Perrig-Chiello, \& A. Walker (Eds.). Hope for a good life: young adults. In A. Krafft, P. Perrig-Chiello, \& A. Walker (Eds.). Hope for a good life:
Results of the Hope Barometer International Research Program (pp. 63-77). Results of the Hope
Dordrecht: Springer.

Guse, T., \& Vermaak, Y. (2011). Hope, psychosocial well-being and socioeconomic status among a group of South African adolescents. Journal of Psychology in Africa, 21(4), 527-534. https://doi.org/10.1080/14330237.2011.10820493

Habib, A. (2016) Transcending the past and reimagining the future of the South African University. Journal of Southern African Studies, 42(1), 35-48. https://doi. org/10.1080/03057070.2016.1121716

Hirschi, A. (2014). Hope as a resource for self-directed career management Investigating mediating effects on positive career behaviors and life and job satisfaction. Journal of Happiness Studies, 15, 1495-1512. https://doi. org/10.1007/s10902-013-9488-x

Hofstede, G. (2011). Dimensionalizing cultures: The Hofstede model in context. In Online readings in psychology and culture, unit 2. Retrieved from http:// scholarworks.gvsu.edu/orpc/vol2/iss1/8

Hu, L.T., \& Bentler, P.M. (1999). Cutoff criteria for fit indixes in covariance structure analysis: Conventional criteria versus new alternatives. Structural Equation Modeling, 6(1), 1-55. https://doi.org/10.1080/10705519909540118

Joshanloo, M. (2016a). A new look at the factor structure of the MHC-FS in Iran and the United States using exploratory structural equation modeling. Journal of the United States using exploratory structural equation modeling. Jour
Clinical Psychology, 72(7), 701-713. https://doi.org/10.1002/jclp.22287

Joshanloo, M. (2016b). Factor structure of subjective well-being in Iran. Journal of Personality Assessment, 98(4), 435-443. https://doi.org/10.1080/00223891.2015 .1117473

Kashdan, T.B., Gallagher, M.W., Silvia, P.J., Winterstein, B.P., Breen, W.E., Terhar, D., \& Steger, M.F. (2009). The curiosity and exploration inventory-II: Development, factor structure, and psychometrics. Journal of Research in Personality, 43(6), 987-998. https://doi.org/10.1016/j.jrp.2009.04.011

Kemer, G., \& Atik, G. (2012). Hope and social support in high school students from urban and rural areas of Ankara, Turkey. Journal of Happiness Studies, 13(5) 901-911. https://doi.org/10.1007/s10902-011-9297-z

Khumalo, I.P., Ejoke, U.P., Asante, K.O., \& Rugira, J. (2021). Measuring social well-being in Africa: An exploratory structural equation modelling study. African Journal of Psychological Assessment, 3(0), a37. https://doi.org/10.4102/ajopa.v3i0.37

Khumalo, I.P., Wilson, A., \& Brouwers, S.A. (2020). Well-being orientations and time perspective across cultural tightness-looseness latent classes in Africa. Journal of
Happiness Studies, 21, 1681-1703. https://doi.org/10.1007/s10902-019-00151-5

Krafft, A.M., Martin-Krumm, C., \& Fenouillet, F. (2017). Adaptation, further elaboration, and validation of a scale to measure hope as perceived by people: Discriminant value and predictive utility vis-à-vis dispositional hope. Assessment, 26(8), 1594-1609. https://doi.org/10.1177/1073191117700724

Liu, S.R., Kia-Keating, M., \& Modir, S. (2017). Hope and adjustment to college in the context of collective trauma. Journal of American College Health, 65(5), 323-330. https://doi.org/10.1080/07448481.2017.1312412

Maree, D.J.F., \& Maree, M. (2005). Assessment of hope and the process of constructing a gender-sensitive scale for hope within a South African context. Paper presented at the Hope: Probing the boundaries conference, Prague, Czech Republic, 8-10 August, 2005

Maree, D.J.F., Maree, M., \& Collins, C. (2008). Constructing a South African hope measure. Journal of Psychology in Africa, 18(1), 167-178. https://doi.org/10.108 $0 / 14330237.2008 .10820183$

Marsh, H.W., Liem, G.A.D., Martin, A.J., Morin, A.J.S., \& Nagengast, B. (2011) Methodological measurement fruitfulness of exploratory structural equation modelling (ESEM): New approaches to key substantive issues in motivation and engagement. Journal of Psychoeducational Assessment, 29(4), 322-346. https:// doi.org/10.1177\%2F0734282911406657

Marsh, H.W., Morin, A.J.S., Parker, P.D., \& Kaur, G. (2014). Exploratory structura equation modelling: An integration of the best features of exploratory and confirmatory factor analysis. Annual Review of Clinical
https://doi.org/10.1146/annurev-clinpsy-032813-153700

Marques, S.C., Lopez, S.J., Rose, S., \& Robinson, C. (2014). Measuring and promoting hope in schoolchildren. In M.J. Furlong, R. Gilman \& E.S. Huebner (Eds.), Handbook of positive psychology in schools ( 2 nd ed.). New York, NY: (Eds.), Hand

Mbiti, J.S. (1990). African religions and philosophy. London: Clays Ltd.

Mbiti, J.S. (1991). Introduction to African religion (2nd ed.). Oxford: Heinemann.

Muthén, L.K., \& Muthén, B.O. (1998-2017). Mplus statistical analysis with latent variables: Users' guide (8th ed.). Los Angeles, CA: Muthén \& Muthén. 
Nel, P., \& Boshoff, A. (2014). Factorial invariance of the Adult State Hope Scale. South African Journal of Industrial Psychology, 40(1), 01-08. https://doi.org/10.4102/ sajip.v40i1.1177

O'Sullivan, G. (2011). The relationship between hope, stress, self-efficacy, and life satisfaction among undergraduates. Social Indicators Research, 101(1), 155-172. https://doi-org.ufs.idm.oclc.org/10.1007/s11205-010-9662-z

Park, E., \& Kim, J. (2017). The factor structure of the Dispositional Hope Scale in hemiplegic stroke patients. Journal of Mental Health, $0(0), 1-6$. https://doi.org/1 $0.1080 / 09638237.2017 .1385735$

Perry, J.L., Nicholls, A.R., Clough, P.J., \& Crust, L. (2015). Assessing model fit: Caveats and recommendations for confirmatory factor analysis and exploratory structural equation modeling. Measurement in Physical Education and Exercise Science, 19(1), 12-21. https://doi.org/10.1080/1091367X.2014.952370

Pretorius, T.B. (2021). Over reliance on model fit indices in confirmatory factor analyses may lead to incorrect inferences about bifactor models: A cautionary note. African Journal of Psychological Assessment, 3(0), a35. https://doi. org/10.4102/ajopa.v3i0.35

Roesch, S.C., \& Vaughn, A.A. (2006). Evidence for the factorial validity of the Dispositional Hope Scale: Cross-ethnic and cross-gender measurement equivalence. European Journal of Psychological Assessment, 22(2), 78-84. https:// doi.org/10.1027/1015-5759.22.2.78

Ryan, R.M. (ed.). (2012). The Oxford handbook of human motivation. Oxford: Oxford University Press.

Ryff, C.D., \& Singer, B. (1998). The contours of positive human health. Psychological Inquiry, 9(1), 1-28. https://doi.org/10.1207/s15327965pli0901_1

Savahl, S., Casas, F., \& Adams, S. (2016). Validation of the children's hope scale amongst a sample of adolescents in the Western Cape Region of South Africa. Child Indicators Research, 9(3), 701-713. https://doi.org/10.1007/s12187-0159334-2

Scheier, M.F., \& Carver, C.S. (1985). Optimism, coping, and health: Assessment and implications of generalized outcome expectancies. Health Psychology, 4(3), 219-247. https://psycnet.apa.org/doi/10.1037/0278-6133.4.3.219

Schnell, T. (2009). The sources of meaning and meaning in life questionnaire (SoMe) Relations to demographics and well-being. The Journal of Positive Psychology, 4(6), 483-499. https://doi.org/10.1080/17439760903271074

Scioli, A., Ricci, M., Nyugen, T., \& Scioli, E. (2011). Hope: Its nature and measurement. Psychology of Religion and Spirituality, 3(2), 78-97. https://doi.org/10.1037/ a0020903

Seligman, M.E.P., \& Csikszentmihalyi, M. (2000). Positive psychology: An introduction. American Psychologist, 55(1), 5-14. https://doi.org/10.1037/0003 066X.55.1.5

Snyder, C.R. (1995). Conceptualizing, measuring, and nurturing hope. Journal of Counselling and Development, 73(3), 355-360. https://doi.org/10.1002/j.15566676.1995.tb01764.x

Snyder, C.R. (2002). Hopeful theory: Rainbows in the mind. Psychological Inquiry, 13(4), 249-275. https://doi.org/10.1207/S15327965PLI1304_01
Snyder, C.R. (2004). Hope and the other strengths: Lessons from animal farm. Journal of Social and Clinical Psychology, 23(5), 624-627. https://doi.org/10.1521/ jscp.23.5.624.50751

Snyder, C.R., Cheavens, J., \& Sympson, S.C. (1997). Hope: An individual motive for social commerce. Group Dynamics: Theory, Research, and Practice, 1(2), 107-118. https://doi.org/10.1037/1089-2699.1.2.107

Snyder, C.R., Harris, C., Anderson, J.R., Holleran, S.A., Irving, L.M., Sigmon, S.T., ... Harney, P. (1991). The will and the ways: Development and validation of an individual-differences measure of hope. Journal of Personality and Socia Psychology, 60(90), 570-585. https://doi.org/10.1037/0022-3514.60.4.570

Snyder, C.R., Hoza, B., Pelham, W.E., Rapoff, M., Ware, L., Danovsky, M., ... Stahl, K.J. (1997). The development and validation of the Children's Hope Scale. Journa of Pediatric Psychology, 22(3), 399-421. https://doi.org/10.1093/jpepsy/22.3.399

Snyder, C.R., Shorey, H.S., Cheavens, J., Pulvers, K.M., Adams III, V.H., \& Wiklund, C. (2002). Hope and academic success in college. Journal of Educational Psychology, 94(4), 820-826. https://doi.org/10.1037/0022-0663.94.4.820

Snyder, C.R., Sympson, S.C., Michael, S.T., \& Cheavens, J. (2000). The optimism and hope constructs: Variants on a positive expectancy theme. In E.C. Chang (Ed.), Optimism and pessimism (pp. 103-124). Washington, DC: American Psychological Association.

Snyder, C.R., Sympson, S.C., Ybasco, F.C., Borders, T.F., Babyak, M.A., \& Higgins, R.L. (1996) Development and validation of the State Hope Scale. Journal of Personality and Social Psychology, 70(2), 321-335. https://doi.org/10.1037/0022-3514.70.2.321

Steger, M.F. (2012). Experiencing meaning in life: Optimal functioning at the nexus of well-being, psychopathology, and spirituality. In P.T. Wong (ed.) The human quest for meaning (2nd ed., pp. 165-184). New York: Routledge.

Stotland, E. (1969). The psychology of hope. San Francisco, CA: Jossey-Bass.

Sun, Q., Ng, K.M., \& Wang, C. (2012). A validation study on a new Chinese version of the Dispositional Hope Scale. Measurement and Evaluation in Counseling and Development, 45(2), 133-148. https://doi.org/10.1177\%2F0748175611429011

Venning, A.J., Eliott, J., Kettler, L., \& Wilson, A. (2009). Normative data for the Hope Scale using Australian adolescents. Australian Journal of Psychology, 61(2), 100-106. https://doi.org/10.1080/00049530802054360

Wang, J., \& Wang, X. (2012). Structural equation modeling: Applications using mplus. West Sussex: Wiley.

Weis, R., \& Speridakos, E.C. (2011). A meta-analysis of hope enhancement strategies in clinical and community settings. Psychology of Well-Being: Theory, Research and Practice, 1(1), 5. https://doi.org/10.1186/2211-1522-1-5

Wissing, M.P., \& Temane, Q.M. (2008). The structure of psychological well-being in cultural context: Towards a hierarchical model of psychological health. Journal of Psychology in Africa, 18(1), 45-56. https://doi.org/10.1080/14330237.2008. 10820170

Wissing, M.P., Thekiso, S.M., Stableberg, R., Van Quickelberg, L., Choabi, P., Moroeng C.,... Vorster, H.H. (2010). Validation of three Setswana measures for psychological wellbeing. South African Journal of Industrial Psychology, 36(2), Art \#860, 8 pages. https://doi.org/10.4102/sajip.v36i2.860 